\title{
Application of a Novel Fiber-Optic Biosensor In Situ to Investigate the Metabolic Effect of Lactate Infusion
}

Stephen R. Dager, M.D., Jeffrey B. Yim, M.S., Gamal E. Khalil, Ph.D., Alan A. Artru, M.D., Douglas M. Bowden, M.D., and Margaret A. Kenny, Ph.D.

Recently developed biosensor technology, which allows near real-time measurement in situ of gas tension $\left(\mathrm{pCO}_{2}\right.$ and $\mathrm{pO}_{2}$ ) and of $\mathrm{pH}$, was applied to arterial blood, cerebrospinal fluid (CSF), and brain parenchyma during intravenous lactate infusion in monkeys. Comparison of simultaneous biosensor measurements and discrete arterial blood sampling for traditional blood gas analyses indicated a high level of correlation for $p \mathrm{CO}_{2}, p \mathrm{O}_{2}$, and $p H$. Arterial $\mathrm{pO}_{2}$ and $\mathrm{pH}$ values were significantly higher and $p \mathrm{CO}_{2}$ significantly lower than corresponding CSF and brain parenchyma values at baseline, during and following lactate infusion. There was a divergence between arterial and brain parenchyma $\mathrm{pH}$ and $\mathrm{pO}_{2}$ measurements. Lactate infusion was associated with progressive arterial $\mathrm{pH}$ rises, consistent with the production of a metabolic alkalosis. Cerebrospinal fluid $p \mathrm{CO}_{2}$ remained unchanged during and following lactate infusion. Brain parenchyma exhibited a complex pattern of response characterized by a trend for $\mathrm{pO}_{2}$ and $\mathrm{pH}$ to decrease during lactate infusion, which reversed following completion of the infusion. These observations are suggestive of a transient hypoxia from decreased cerebral blood flow and/or reduced oxyhemoglobin dissociation during lactate infusion, but verification of these results is required. [Neuropsychopharmacology 12:307-313, 1995]
KEY WORDS: Fiber-optic biosensor; Gas tension $\left(\mathrm{pO}_{2}\right.$, $\left.p \mathrm{CO}_{2}\right)$; $\mathrm{pH}$; Brain; Lactate infusion; Panic disorder

Intravenous infusion of sodium lactate can produce intense psychological and physiological symptoms characteristic of a panic response in susceptible individuals (Bonn et al. 1971; Dager et al. 1987; Fink et al. 1970; Kelly et al. 1971; Knot et al. 1981; Liebowitz et al. 1984; Pitts and McClure 1967; Rainey et al. 1984). Although the mechanism remains undetermined, a positive response

From the departments of Psychiatry and Behavioral Sciences (SRD, DMB), Bioengineering (SRD), Chemical Engineering (GEK), Anesthesiology (AAA), Laboratory Medicine (MAK), and Regional Primate Research Center (SRD, DMB), University of Washington, Seattle, WA; and Abbott Research (JBY, GEK), Seattle, WA.

Address correspondence to: Dr. Dager, University of Washington Outpatient Psychiatry, 4225 Roosevelt Way NE, Suite 306, Seattle, WA 98105.

Received November 15, 1993; revised October 20, 1994; accepted November 1, 1994. to lactate infusion appears to be a sensitive and specific marker for naturally occurring panic attacks (Cowley and Arana 1990).

Previous work using mechanically ventilated monkeys to investigate central nervous system (CNS) effects of intravenous sodium lactate infusion reported increases in lactate, as well as delayed increases in $\mathrm{pH}$ and bicarbonate using a technique of intermittent direct sampling of cisternal CSF (Dager et al. 1990). Contrary to theories that lactate-induced panic results from peripheral metabolism of lactate to $\mathrm{CO}_{2}$ that then rapidly crosses the blood-brain barrier (Gorman 1989), in the Dager et al. (1990) study CSF $\mathrm{pCO}_{2}$ levels did not increase during lactate infusion. However, it is uncertain whether the intermittent removal of cisternal CSF may have affected those results and whether CSF $\mathrm{pCO}_{2}$ is representative of parenchymal brain $\mathrm{pCO}_{2}$.

Accordingly, the present study was designed to continuously monitor gas tension $\left(\mathrm{pO}_{2}\right.$ and $\left.\mathrm{pCO}_{2}\right)$ and 
$\mathrm{pH}$ with indwelling proprietary fiber-optic probes in situ in arterial blood, CSF, and brain parenchyma during lactate infusion in monkeys. A unique feature of the emerging technology of fiber-optic biosensors is the capability to obtain measurements unaffected by potential volume depletion effects due to repeated sampling. The on-line capabilities of these instruments also allow simultaneous, near real-time assessment of rapidly changing metabolic conditions between compartments.

The purpose of this study was to use a fiber-optic biosensor to reexamine our previous findings of CSF changes in monkeys (Dager et al. 1990) and to further assess the temporal relationship between blood, CSF, and brain interstitial fluid gas tension and $\mathrm{pH}$ changes in mechanically ventilated monkeys during lactate infusion.

\section{METHODOLOGY}

Seven healthy, adult pig-tailed macaques (Macaca nemestrina) weighing $8.3 \pm 3.2 \mathrm{~kg}$ were studied. The study was approved by the University of Washington Animal Care Committee and conducted at the Regional Primate Research Center at the University of Washington. Two animals were restudied and the two sets of measurements averaged for each twice-studied monkey (each of the twice-studied animals had missing CSF or brain parenchyma data for one experiment). One of the seven animals was continuously monitored for 24 hours between repeat lactate infusions. Animals were initially anesthetized with ketamine $(10 \mathrm{mg} / \mathrm{kg} \mathrm{IM})$, and the trachea was intubated. Anesthesia was maintained during the experiment with halothane, $0.5-1.0 \%$ inspired in air. Animals were mechanically ventilated at a constant minute ventilation using a Harvard Ventilator (Harvard Apparatus Co., Dover, MA) to maintain initial $\mathrm{PaCO}_{2}$ at approximately $40 \mathrm{mmHg}$. Body temperature was maintained between $37^{\circ} \mathrm{C}$ and $38^{\circ} \mathrm{C}$ using a thermoregulated, circulating-water blanket placed under the animal. An 18-gauge catheter was inserted into a radial vein for lactate administration. Incisions were made over both femoral arteries and fiber-optic biosensors were inserted bilaterally via femoral arteriotomies. These probes are designed to permit arterial blood sampling for discrete blood gas analyses (Bertaud et al. 1990), which was alternated between locations during the experiments.

After placement of the arterial probes, the scalp was incised and reflected and $0.5-\mathrm{cm}$ holes were drilled through the cranium bilaterally over the parietal cortex. On one side, the dura was pierced, and a \#5 French feeding tube placed between the dura and pia to allow the insertion of the biosensor probe and to ensure constant bathing of the probe tip in CSF. On the contralateral hemisphere, a stereotaxic apparatus was used to insert a biosensor probe tip through the dura approximately $5 \mathrm{~mm}$ into the brain. Two animals had bilateral brain probes placed to allow simultaneous comparison between locations. Following insertion, the dura was sutured and the probes glued into place (Kool Liner) to stabilize the probe tips and block fluid leakage.

Following stabilization of arterial blood gases for 20 minutes, $1 \mathrm{M}$ racemic sodium lactate (Abbott Laboratories), $10 \mathrm{ml} / \mathrm{kg}$, was infused intravenously over 20 minutes at 4 to $6 \mathrm{ml} /$ minute. Discrete arterial blood samples were obtained before, during, and after infusion of lactate to compare with biosensor values. Gas tension measurements from arterial blood samples were performed using a Corning Model 178 Blood Gas Analyzer capable of analyzing $0.1-\mathrm{ml}$ samples. Throughout the experiment instrument performance was routinely calibrated against standard buffers. Lactate concentrations at baseline and completion of lactate infusion were determined from arterial blood samples collected into gray-top tubes (Becton Dickinson) containing sodium fluoride and potassium oxalate. Blood samples were filtrated by adding $0.6 \mathrm{~mol} / \mathrm{L}$ perchloric acid and then vortexing. L-lactate in the supernatant was assayed using an automated enzymatic, L-lactate dehydrogenase procedure (Hohorst 1963) and D-lactate levels determined using a soluble D-lactate from Leishmanii and spectrophotometric quantification (Garvel and Bergmeyer 1974).

The biosensor is a sterile, disposable fiber-optic device designed for insertion into arterial blood through a 20 Ga catheter (1-3/4" Arrow Arterial Catheter or 2" Deseret Insyte) (Narayanas-Wamy 1991). The tip of the device, which resides in a fluid sample, consists of analyte-specific, nonconsumptive polymeric dye and membrane systems bound to three $120-\mu$-diameter fiber optics. The measurement technology is designed to minimize transient motion artifacts common in some fiber-optic devices specifically through the use of reference wavelengths and ratiometric algorithms that compensate for noncatastrophic light loss due to optical fiber motion (Guiliani and Gutcheck 1990). The reliability and accuracy of this probe have been extensively tested (Iyer et al. 1990, 1991).

For the $\mathrm{pH}$ and $\mathrm{CO}_{2}$ sensors, changes in analyte concentration are detected by wavelength-specific changes in the absorbance of indicator dyes. The $\mathrm{pH}$ dye system is coupled to the optical fiber using pellets of polymerically bound dye adhered to a reflective surface (Iyer et al. 1990, 1991). The instrument alternately transmits two wavelengths of light that pass through the measurement cell and return to the instrument photodetectors after reflecting off the cell mirror. Changes in $\mathrm{pH}$ result in differential absorbance through the $\mathrm{pH}$ cell that are detected by the instrument as changes in returning light intensity. The carbon dioxide sensor embodies a modified Severinghaus principle in which 
bicarbonate is mixed with a $\mathrm{pH}$ indicator dye (Vurek et al. 1983). The $\mathrm{CO}_{2}$ pellet is embedded in a gas-permeable hydrophobic polymer. $\mathrm{CO}_{2}$ is measured as changes in the internal $\mathrm{pH}$ of the sensor that produce differential absorbance changes of the indicator dye. The oxygen-sensing chemistry employs a phosphorescent dye whose emission is proportional to the partial pressure of oxygen. The dye is mixed with a hydrophobic gas-permeable polymer and applied to the end of an optical fiber. Light at one of the dye excitation wavelengths is pulsed down the fiber, and the dye emits a second wavelength in response. The oxygen concentration of the fluid sample is proportional to the ratio of two luminescent decay times of the dye emission (Khalil et al. 1991). The three sensors and a thermocouple are integrated into a sensor bundle or probe designed for durability and thrombo-resistance (Yim et al. 1991). The thermocouple is necessary to measure the probe location temperature that allows gas tensions to be corrected relative to $37^{\circ} \mathrm{C}$.

\section{ANALYSIS}

Probe values were assessed in relationship to standard arterial blood gas and $\mathrm{pH}$ analyses and between brain probes located in opposite hemispheres using Pearson's correlation coefficient. Three data points from each probe were collected per minute and data averaged over 5-minute intervals (four baseline, four lactate infusion, and four postlactate infusion timepoints). Gas tension and $\mathrm{pH}$ differences between compartments and differential changes in response to lactate infusion were assessed by two-way analysis of variance (ANOVA) for repeated measure using the Greenhouse-Geisser correction; if significant, Scheffe's test was applied for comparisons at each time point between locations. As twoway ANOVAs were significant or indicated a trend for time-by-location effects, a one-way ANOVA for repeated measures, applying the Greenhouse-Geisser correction, was used to assess gas tension and $\mathrm{pH}$ changes separately at each location over the 12 averaged time points at baseline, during, and after completion of lactate infusion.

Additional post-hoc analyses applying a repeatedmeasures ANOVA to examine time-by-location effects, excluding CSF data, were performed for exploratory analysis of the divergence between brain parenchyma and arterial measurements during lactate infusion.

\section{RESULTS}

Comparison of simultaneous biosensor measurements and discrete arterial blood sampling for traditional blood gas analyses indicated a high level of correlation for
$\mathrm{pCO}_{2}(r=.95 ; \mathrm{df}=101 ; p<.001), \mathrm{pO}_{2}(r=.91 ; \mathrm{df}=$ $101 ; p<.001)$, and $\mathrm{pH}(r=0.95 ; \mathrm{df}=101 ; p<.001)$. There was also a strong correlation at each time point for two animals in which brain probes were placed bilaterally in opposite hemispheres for $\mathrm{pCO}_{2}(r=0.83$; $\mathrm{df}=87 ; p<.001), \mathrm{pO}_{2}(r=0.61 ; \mathrm{df}=87 ; p<.001$, and $\mathrm{pH}(r=0.84 ; \mathrm{df}=87 ; p<.001)$.

During lactate infusion arterial blood lactate (combined concentration of D- and L-lactate) rose from $2.7 \pm$ $1.0 \mathrm{mM} / \mathrm{L}$ (all values $\pm \mathrm{SD}$ ) at baseline to $18.9 \pm 5.9$ $\mathrm{mM} / \mathrm{L}$ at completion of the infusion.

The relationship between $\mathrm{pCO}_{2}$ levels at baseline, during, and after completion of lactate infusion for the three probe locations is shown in Figure 1. Significant differences in $\mathrm{pCO}_{2}$ levels were observed between the three locations according to a repeated-measures ANOVA $[F(2,18)=8.06 ; p<.003 ; e=.204]$. This was due to consistently lower arterial $\mathrm{pCO}_{2}$ levels than CSF $\mathrm{PCO}_{2}$ (Scheffe's test, $p<.05$ ) and brain parenchyma $\mathrm{pCO}_{2}$ (Scheffe's test, $p<.01$ ) levels. Time effects on $\mathrm{pCO}_{2}$ values pooled across locations were nonsignificant $[F(11,231)=1.39 ; p=N S]$, but a trend for timeby-location differences was observed $[F(22,198)=2.03$; $p<0.1]$. This trend remained when a post hoc ANOVA for location by time, excluding CSF data, was performed for arterial $\mathrm{pCO}_{2}$ and brain parenchyma $\mathrm{pCO}_{2}$ measurements $[F(11,132)=2.71 ; p<0.1 ; e=.173]$.

As a nonsignificant trend for time-by-location differences was detected, and to remain consistent with the other analyses, a one-way ANOVA for repeated measures was used to examine each location separately. A trend was observed for arterial $\mathrm{pCO}_{2}$ to gradually decrease during the experiment $[F(11,66)=3.46 ; p<.09$;

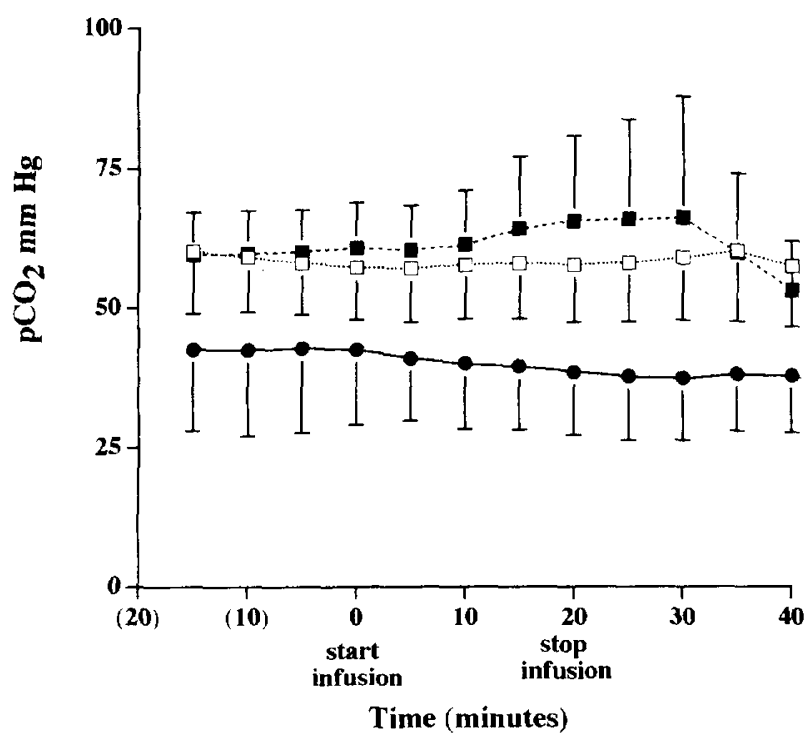

Figure 1. Mean arterial $\mathrm{pCO}_{2}$ (circles), $\mathrm{CSF} \mathrm{pCO}_{2}$ (blank squares), and brain parenchyma $\mathrm{pCO}_{2}$ (solid squares) at baseline, during, and after lactate infusion $( \pm S D)$. 


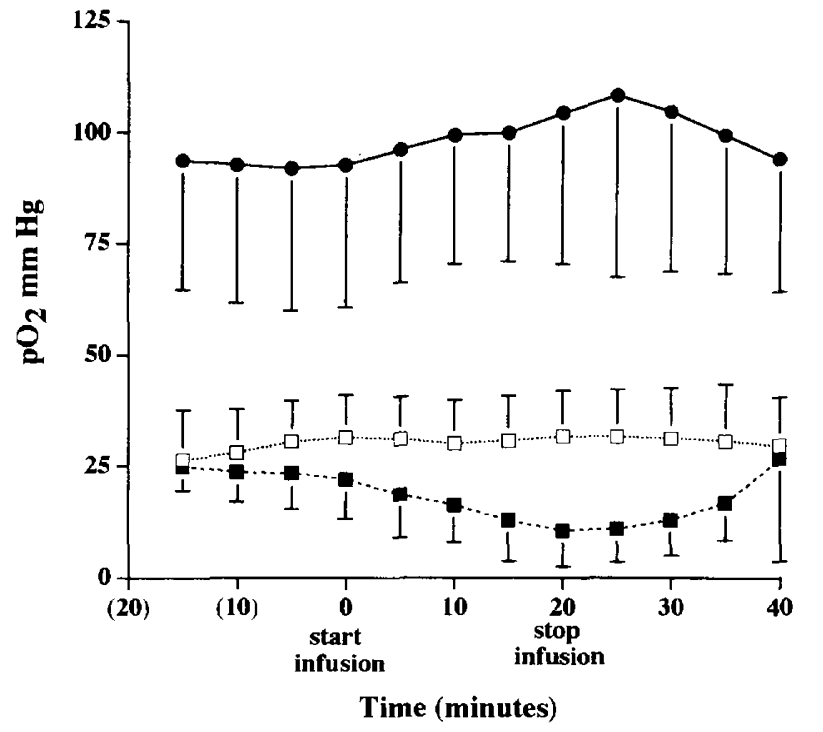

Figure 2. Mean arterial $\mathrm{pO}_{2}$ (circles), $\mathrm{CSF} \mathrm{pO}_{2}$ (blank squares), and brain parenchyma $\mathrm{pO}_{2}$ (solid squares) averaged every 5 minutes at baseline, during, and after lactate infusion $( \pm S D)$.

$e=.120]$. Baseline CSF $\mathrm{pCO}_{2}$ levels varied between $60.2 \pm 11.2 \mathrm{mmHg}$ and $57.3 \pm 9.5 \mathrm{mmHg}$ and did not significantly change in response to lactate infusion $[F(11,66)=0.74 ; p=\mathrm{NS} ; e=.142]$. Brain parenchyma $\mathrm{pCO}_{2}$ levels did not substantially change during baseline, between $59.5 \pm 7.6 \mathrm{mmHg}$ and $60.8 \pm 8.1 \mathrm{mmHg}$, increased nonsignificantly during and immediately postinfusion to $66.2 \pm 21.8 \mathrm{mmHg}$, and then decreased to $53.2 \pm 8.9 \mathrm{mmHg}$ during the final 10 minutes of postinfusion monitoring $[F(11,66)=1.75 ; p=\mathrm{NS} ; e=.157]$.

The relationship between $\mathrm{pO}_{2}$ levels at baseline, during, and after completion of lactate infusion for the three probe locations is shown in Figure 2. Significant differences in $\mathrm{pO}_{2}$ levels were observed between the three locations according to a repeated-measures ANOVA $[F(2,18)=29.76 ; p<.001 ; e=.253)$. This was due to consistently higher arterial $\mathrm{pO}_{2}$ levels in comparison to CSF $\mathrm{pO}_{2}$ (Scheffe's test, $p<.0001$ ) and brain parenchyma $\mathrm{pO}_{2}$ (Scheffe's test, $p<.0001$ ) levels. Time effects on $\mathrm{pO}_{2}$ values pooled across locations were nonsignificant $[F(11,231)=0.21 ; p=\mathrm{NS}]$; however, a significant time-by-location effect was observed $[F(22,198)=4.05, p<.003]$. A post hoc ANOVA for location by time, excluding CSF data, remained significant when performed for arterial $\mathrm{pO}_{2}$ and brain parenchyma $\mathrm{pCO}_{2}$ measurements $[F(11,132)=6.01 ; p<$ $.003 ; e=.236]$.

As there was a significant time-by-location effect, a one-way repeated-measures ANOVA was used to compare each location separately. Arterial $\mathrm{pO}_{2}$ values nonsignificantly increased from $92.7 \pm 32 \mathrm{mmHg}$ to $104.5 \pm 34 \mathrm{mmHg}$ during lactate infusion. $[F(11,66)=$ 2.71; $p=\mathrm{NS} ; e=.132]$. Baseline variations in $\mathrm{CSF} \mathrm{pO}_{2}$

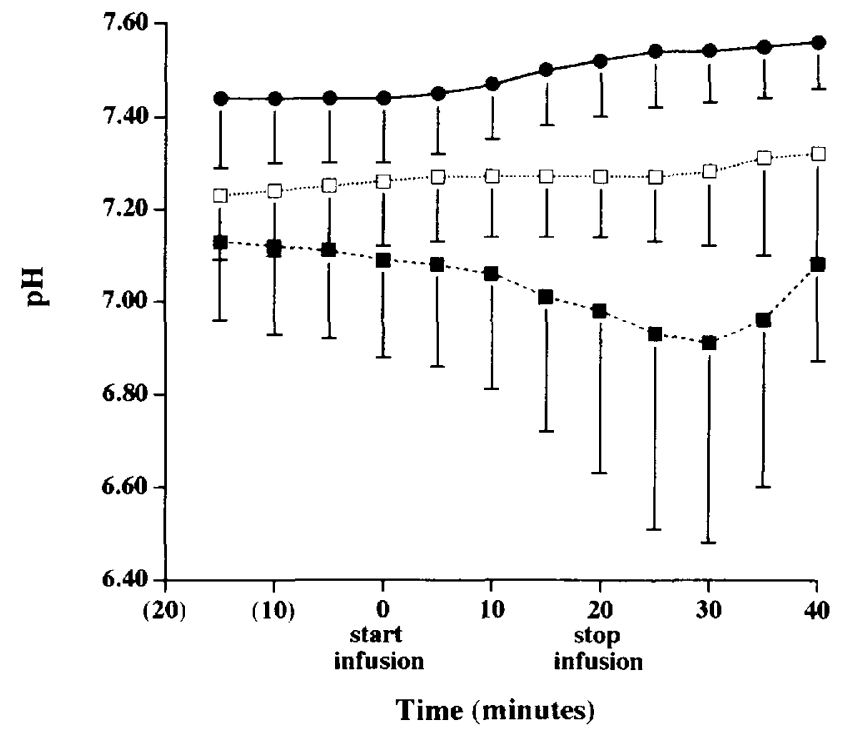

Figure 3. Mean arterial pH (circles), CSF pH (blank squares), and brain parenchyma $\mathrm{pH}$ (solid squares) averaged every 5 minutes at baseline, during, and after lactate infusion $( \pm S D)$.

levels, between $26.4 \pm 17.5 \mathrm{mmHg}$ and $31.5 \pm 18.6$ $\mathrm{mmHg}$, were greater than any changes in response to lactate infusion $[F(11,66)=0.73 ; p=\mathrm{NS} ; e=.126]$. Brain parenchyma $\mathrm{pO}_{2}$ values decreased by a small amount during baseline, from $24.9 \pm 5.4 \mathrm{mmHg}$ to $22.1 \pm 8.8$ $\mathrm{mmHg}$, progressively decreased to $10.6 \pm 8.0 \mathrm{mmHg}$ during lactate infusion, and then increased above baseline to $26.6 \pm 23.1 \mathrm{mmHg}$ at the end of the postinfusion period $[F(11,66)=3.64 ; p<.08 ; e=.139]$.

The relationship between $\mathrm{pH}$ at baseline, during, and after lactate infusion for the three probe locations is shown in Figure 3. Significant differences in $\mathrm{pH}$ levels were observed between the three locations according to two-way, a repeated-measures ANOVA $[F(2,18)=$ 9.73; $p<.002 ; e=.157]$. This was due to a trend for arterial $\mathrm{pH}$ to be higher than CSF $\mathrm{pH}$ levels (Scheffe's test, $p<.09$ ) and significantly higher than brain parenchymal pH (Scheffe's test, $p<.001$ ). A time effect on $\mathrm{pH}$ values pooled across locations was nonsignificant $[F(11,231)=1.4 ; p=N S]$. However, a time-by-location effect was observed $[F(22,198)=5.2 ; p<.004)$. This time-by-location effect remained significant when a post hoc ANOVA excluding CSF data was performed for arterial $\mathrm{pH}$ and brain parenchyma $\mathrm{pH}$ measurements $[F(11,132)=7.85 ; p<.009 ; e=.119]$.

As there was a significant time-by-location effect, a one-way repeated-measures ANOVA was used to compare each location separately. Arterial $\mathrm{pH}$ values remained stable during baseline, at approximately $7.44 \pm 0.14$, then progressively increased during and following lactate infusion to $7.56 \pm .10[F(11,66)=15.50$; $p<.002 ; e=.135]$. Baseline CSF pH levels varied between $7.23 \pm 0.14$ to $7.26 \pm .14$, then increased non- 
significantly during and postinfusion to $7.32 \pm 0.23$ $[F(11,66)=1.29 ; p=\mathrm{NS} ; e=.107]$. Brain parenchyma $\mathrm{pH}$ levels decreased slightly during baseline, from $7.13 \pm 0.17$ to $7.09 \pm 0.21$, progressively decreased to $6.91 \pm .043$ during and immediately postinfusion, and then increased back to $7.08 \pm 0.21$ during the final 10 minutes of the postinfusion period $[F(11,66)=3.6 ; p<$ $.09 ; e=.110]$.

After completion of the lactate infusion, one animal was observed during a 24-hour period of continuous blood, CSF, and brain parenchyma biosensor monitoring followed by a second lactate infusion. Probe values remained stable during the 24 hours between lactate infusions. During both lactate infusions, a similar brain parenchyma response pattern occurred, characterized by substantial decreases in $\mathrm{pO}_{2}$ and $\mathrm{pH}$ and by a slight increase in $\mathrm{pCO}_{2}$ that reversed upon completion of the infusion.

\section{DISCUSSION}

These data demonstrate the first application of a novel fiber-optic biosensor in situ to study peripheral and $\mathrm{CNS} \mathrm{pO}_{2}, \mathrm{pCO}_{2}$, and $\mathrm{pH}$ responses to a metabolic challenge. Analysis of these data was limited by the power that precluded more extensive modeling using time-series analysis or multivariate analysis, but it did allow a preliminary assessment of the time course and compartmental differences in gas tension and $\mathrm{pH}$ changes. Metabolic changes were induced by intravenous infusion of sodium lactate, which also is used to precipitate panic in susceptible humans who experience spontaneous panic attacks. Although within the range previously used by us to study CNS effects of lactate infusion in monkeys (Dager et al. 1990), the amount of lactate administered was approximately double the dose generally received by humans during a standard lactate infusion and thus may limit clinical extrapolation of this work. In addition, hyperventilation, which is associated with lactate-induced panic and has been shown to significantly affect brain metabolism in humans (Dager et al. 1995), was controlled for in this experiment.

The fiber-optic biosensor demonstrated good agreement in comparison to discrete arterial blood gas and $\mathrm{pH}$ measurements obtained using a standard blood gas instrument to analyze direct sampling of arterial blood. In addition to the advantages of in situ monitoring under near real-time conditions, problems with discrete arterial blood sampling, such as, systematic errors due to air bubbles (Biswas et al. 1982; Harsten et al. 1988; Thorson et al. 1983), dilution from flush solution (Boidin and Jorna, 1984; Hamilton et al. 1978), storage temperature, or time delay between sampling and measurement (Kelman and Nunn 1966) were avoided using fiber-optic biosensor technology. The biosensor technology described in this report utilized phosphorescence; however, alternative technological approaches using fluorescence or micro electrodes also have been developed for fiber-optic biosensors (Barker and Hyatt 1991; Mahutte et al. 1990; Shapiro 1992; Shapiro et al. 1989) and could be similarly applied.

During lactate infusion, a progressive rise detected in arterial $\mathrm{pH}$ is consistent with the metabolic alkalosis observed in humans during lactate infusion (Liebowitz et al. 1985). Arterial $\mathrm{pCO}_{2}$ exhibited a trend to decrease during lactate infusion, but this observation is not directly comparable to human studies that demonstrate a lowering of $\mathrm{pCO}_{2}$ presumably due to hyperventilation in spontaneous ventilating subjects. Thus, the small decreases in arterial $\mathrm{pCO}_{2}$ observed in this study may reflect the effect of increased blood $\mathrm{pH}$ or changes in tissue $\mathrm{CO}_{2}$ production during lactate infusion.

Findings that $\mathrm{CSF} \mathrm{pCO}_{2}$ did not change in response to lactate infusion are consistent with our previous findings (Dager et al. 1990) and a subsequent report wherein $\mathrm{CSF} \mathrm{pCO}_{2}$ did not change at a single sampling point after lactate infusion in spontaneously ventilating monkeys (Coplan et al. 1992). These results provide additional evidence to support our conclusion (Dager et al. 1990) that CNS uptake of excess blood $\mathrm{CO}_{2}$ arising from peripheral lactate metabolism is not the mechanism responsible for lactate-induced panic (Gorman et al. 1989).

The divergence between arterial and brain parenchyma $\mathrm{pH}$ and $\mathrm{pO}_{2}$ levels during lactate infusion was a particularly notable finding of this study. During lactate infusion when arterial $\mathrm{pH}$ and $\mathrm{pO}_{2}$ values were increasing, brain parenchyma $\mathrm{pH}$ and $\mathrm{pO}_{2}$ exhibited a trend to decrease and then to increase back toward or above baseline during the postinfusion period. At the same time there were nonsignificant increases in brain parenchyma $\mathrm{pCO}_{2}$ while arterial $\mathrm{pCO}_{2}$ was decreasing. Although decreases in brain parenchymal $\mathrm{pO}_{2}$ and $\mathrm{pH}$ during baseline may have contributed to the overall trend, those changes were small in comparison to changes during lactate infusion. In addition, brain parenchyma changes were not reflected in CSF changes, which would be consistent with observations that the bulk flow of fluid exchange between brain perivascular space and CSF is both slow and variable in direction (Ichimura et al. 1991). One possible explanation for this divergent pattern of response in the brain parenchyma would be an acute, transient decrease in cerebral blood flow during lactate infusion that would specifically decrease brain tissue $\mathrm{O}_{2}, \mathrm{pH}$, and washout of $\mathrm{CO}_{2}$. While such an interpretation runs counter to evidence from piglets that cerebral blood flow can increase in response to osmolar effects of lactate infusion on the pial arteries (Laptook et al. 1988), it is consistent with observations that infusion of hyperosmolar compounds such as man- 
nitol produce a compensatory reduction in cerebral blood flow when cerebral vessels constrict in response to the hyperemia resulting from decreased blood viscosity (Donato et al. 1994). A second explanation for the pattern of response observed in the brain parenchyma in the present study is decreased oxyhemoglobin dissociation. A reduction in oxyhemoglobin dissociation resulting from the metabolic alkalosis produced by sodium lactate infusion would decrease oxygen delivery (Edvinsson et al. 1993) and accentuate hypoxic effects of a transient decrease in cerebral blood flow.

In our initial effort using direct sampling to evaluate CNS effects of lactate infusion, a rise in cisternal fluid lactate was detected during the infusion (Dager et al. 1990). Subsequent work applying magnetic resonance spectroscopy (MRS) to measure brain lactate noninvasively during lactate infusion has detected rises in brain lactate during lactate infusion in animals (Dager et al. 1992a) and healthy volunteers (Dager et al. 1992b) and disproportionately greater increases among panic subjects during a lactate-induced panic response (Dager et al. 1994). Although brain tissues appear to have limited capacity for oxidative catabolism of lactate under resting conditions (Gjedde et al. 1975; Wortis et al. 1941; Sacks 1965), utilization of lactate by mammalian brain can be demonstrated (Fernandes et al. 1984; Schurr et al. 1988; Sokoloff 1973). Thus, parenchymal brain $\mathrm{pH}$ changes may in part reflect the primary metabolism of elevated brain lactate levels.

Brain parenchyma $\mathrm{pH}$ and gas tension findings were inconsistently observed in all animals, which suggests individual variability in the pattern of response. Concurrent interstitial fluid measurements from contralateral brain locations obtained for comparison in two animals indicated good agreement between probes. However, we are unable to comment with certainty whether brain parenchyma findings may reflect a localized phenomenon influenced by the presence of the probe tip intead of a more generalized effect. It is also unknown whether halothane may have influenced brain interstitial fluid measurements. It is noteworthy that the time course for brain parenchyma gas tension and $\mathrm{pH}$ changes were reproducible in response to repeated lactate infusion in one animal following a 24hour monitoring period during which gas tension and $\mathrm{pH}$ measurements remained stable.

\section{ACKNOWLEDGMENTS}

This work was supported by USPHS Grants BRSG 62-3113, an Individual Faculty Scholar Award (MH19168), and a Regional Primate Research Center award (RR00166) to the University of Washington. Additional equipment and technical support were provided by Abbott Research, Mark Minkus, General Manager. We are grateful for the technical assistance of Doug Hasund, Mark Dubach, Ph.D., and Greg
Metzger and for the manuscript preparation by Marie Domsalla. We thank Walton T. Roth, M.D., Stanford University, and Paul Sampson, Ph.D., University of Washington, for statistical consultation and Donald F. Klein, M.D., Columbia University, for helpful comments on an earlier version of the manuscript. Two of the authors (Jeffrey Yim, M.S., and Gamal Khalil, Ph.D.) hold patents to components of the biosensor probe.

\section{REFERENCES}

Barker SJ, Hyatt J (1991): Continuous measurement of intraarterial $\mathrm{pHa}, \mathrm{PaCO} 2$, and $\mathrm{PaO} 2$ in the operating room. Anesth Analg 73:43-48

Bertaud F, Grabenkort R, Magrane B, Urek G (1990): Sensor delivery device. United States Patent 5,112,309

Biswas CK, Ramos JM, Agroyannis B, Derr DNS (1982): Blood gas analysis: Effect of air bubbles in syringe and delay in estimation. Br Med Journal 284:923-927

Boidin MP, Jorna P (1984): Influence of different heparin solutions upon blood gas analysis and biochemical values measured in plasma. Intens Care Med 10:255-260

Bonn JA, Harrison J, Rees WL (1971): Lactate-induced anxiety: Therapeutic application. Br J Psychiatry 119:468-471

Coplan JD, Sharma T, Rosenblum LA, Friedman S, Bassoff TB, Barbour RL, Gorman JM (1992): Effects of sodium lactate infusion on cisternal lactate and carbon dioxide levels in nonhuman primates. Am J Psychiatry 149(10): 1369-1373

Cowley DS, Arana GW (1990): The diagnostic utility of lactate sensitivity in panic disorder. Arch Gen Psychiatry 47:277-284

Dager SR, Cowley DS, Dunner DL (1987): Biological markers in panic states: Lactate-induced panic and mitral valve prolapse. Biol Psychiatry 22:339-359

Dager SR, Rainey JM, Kenny MA, Artru AA, Metzger GD, Bowden DS (1990): Central nervous system effects of lactate infusion in primates. Biol Psychiatry 27:193-204

Dager SR, Marro KI, Metzger GD, Richards TL (1992a): MRS detection of whole brain lactate rise during $1 \mathrm{M}$ sodium lactate infusion in rats. Biol Psychiatry 32:913-921

Dager SR, Marro KI, Richards TL, Metzger GD (1992b): Localized magnetic resonance spectroscopy measurement of brain lactate during intravenous $0.5 \mathrm{M}$ sodium lactate infusion in healthy volunteers. Life Sciences 51:973-985

Dager SR, Marro KI, Richards TL, Metzger GD (1994): Preliminary applications of $1 \mathrm{H}$ magnetic resonance spectroscopy to investigate lactate-induced panic. Am J Psychiatry 151(1):57-63

Dager SR, Strauss WL, Marro KI, Richards TL, Metzger GD, Artru AA (1995): ${ }^{1} \mathrm{H}$ magnetic resonance spectroscopy investigation of hyperventilation in panic and comparison subjects. Am J Psychiatry 152(5):662-672

Donato T, Shapira Y, Artru AA, Power KM (1993): Effect of mannitol on cerebrospinal fluid diagnosis and brain tissue edemia. Anesth Analg 78:58-66

Edvinsson L, MacKenzie ET, McCulloch J (1993): Changes in arterial gas tensions. In Edvinsson L, MacKenzie ET, McCulloch J. (eds), Cerebral Blood Flow and Metabolism, New York, Raven, pp 524-552 
Fernandes J, Berger R, Smith GPA (1984): Lactate as a cerebral metabolic fuel for glucose-6-phosphatase deficient children. Pediatr Reson 18:335-339

Fink M, Taylor MA, Volavka J (1970): Anxiety precipitated by lactate. $\mathrm{N}$ Engl J Med 281:1429

Garvel VND, Bergmeyer HU (1974): D(-)-lactate. In Bergmeyher HU (ed), Methods of Enzymatic Analysis ed 2 (vol. 3), New York, Academic Press, 1492-1495

Gjedde A, Andersson J, Eklof B (1975): Brain uptake of lactate, antipyrine, water and ethanol. Acta Physiol Scand 93:145-149

Gorman JM, Liebowitz MR, Fyer AJ, Stein J (1989): A neuroanatomical hypothesis for panic disorder. Am J Psychiatry 146:148-161

Guiliani D, Gutcheck R (1990: Optical fiber distribution system for an optical fiber. United States Patent 4,907,857

Hamilton RD, Crockett AJ, Aplers JH (1978): Arterial blood gas analysis: Potential errors due to the addition of heparin. Anaesth Intens Care 3:251-255

Harsten A, Berg B, Inerot S, Muth L (1988): Importance of correct handling of samples for the results of blood gas analysis. Acta Anaesthesiol Scand 32:365-368

Hohorst HJ (1963): L-lactate determination with lactate dehydrogenase and DPN. In Bergmeyher HU (ed), Methods of Enzymatic Analysis, Berlin, Verlag Chemie Weinheim, pp 266-270

Ichimura T, Fraser PA, Cserr HF (1991): Distribution of extracellular tracers in perivascular spaces of the rat brain. Brain Res 545:103-113

Iyer LM, Yim JB, Lyon KS (1990): Fiber-optic Physiologic Probes. United States Patent 4,925,268

Iyer LM, Yim JB, Lyon KS (1991): Fiber-optic Physiologic Probes. United States Patent 5,000,901

Kelly D, Mitchell-Heggs N, Sherman D (1971): Anxiety and the effects of sodium lactate assessed clinically and physiologically. Br J Psychiatry 119:129-141

Kelman GR, Nunn JF (1966): Nonograms for correction of blood $\mathrm{PO}_{2}, \mathrm{PCO}_{2}, \mathrm{pH}$, and base excess for time and temperature. J Appl Physiol 21:1484-1490

Khalil G, Gonteiman M, Green E (1991): Method of Measuring Oxygen Concentration. United States Patent 5,043,286

Knott V, Chaudry R, Lapierre Y (1981): Panic induced by sodium lactate: Electrophysiological correlates. Prog Neuropsychopharmacol 5:511-514

Laptook AR, Peterson J, Porter AM (1988): Effects of lactic acid infusions and $\mathrm{pH}$ on cerebral blood flow and metabolism. J Cereb Blood Flow Metab 8:193-200
Liebowitz MR, Fyer AJ, Gorman JM, Dillon D, Appleby JL, Levy G, Anderson S, Levitt M, Palij M, Davies SO, Klein DF (1984): Lactate provocation of panic attacks: I. Clinical and behavioral findings. Arch Gen Psychiatry 41:764-770

Liebowitz MR, Gorman JM, Fyer AJ, Levitt M, Dillon D, Levy G, Appleby IL, Anderson S, Palij M, Davies SO, Klein DF (1985): Lactate provocation of panic attacks. II. Biochemical and physiological findings. Arch Gen Psychiatry 42:709-719

Mahutte KC, Sassoon SH, Muro JR, Hansmann DR, Maxwell TP, Miller WW, Yafuso M (1990): Progress in the development of a fluorescent intravascular blood gas system in Man. J Clin Monitoring 6:147-157

Narayanas-Wamy R (1991): Current developments in optical biochemical sensors. Biosensors and Bioelectronics 6 : 467-475

Pitts FN, McClure JN (1967): Lactate metabolism in anxiety neurosis. N Engl J Med 177:1329-1336

Rainey JM Jr, Pohl RB, Williams M, et al. (1984): A comparison of lactate and isoproterenol anxiety states. Psychopathology 17(Suppl 1):74-82

Sacks W (1965): The cerebral metabolism of L- and D-lactate$14 \mathrm{c}$ in humans in vivo. Ann NY Acad Sci 119;1091-1108

Schurr A, West CA, Rigor BM (1988): Lactate-supported synaptic function in the rat hippocampal slice preparation. Science 240:1326-1328

Shapiro BA (1992): In-vivo monitoring of arterial blood gases and $\mathrm{pH}$. Respi Care 37:165-169

Shapiro BA, Cane RD, Chomka CM, Bandala LE, Peruzzi WT (1989): Preliminary evaluation of an intra-arterial system in dogs and humans. Crit Care Med 17:455-460

Sokoloff L (1973): Metabolism of ketone bodies by the brain. Ann Rev Med 24:271-280

Thorson SH, Marini JJ, Pierson DJ, Hudson LD (1983): Variability of arterial blood gas values in stable patients in the ICU. Chest 84:14-18

Vurek GG, Feustel PJ, Severinghaus JW (1983): A fiber-optic $\mathrm{pCO}_{2}$ sensor. Ann Biomed Equip 11:499-510

Wortis J, Bowman KM, Goldfarb W, Fazekas JF, Himwich HE (1941): Availability of lactic acid for brain oxidations. J Neurophysiol 4:243-249

Yim JB, Hubbard TW, Melkerson LD, Sexton MA, Fieggen BM (1991): Configuration of a fiber-optic blood gas sensor and method of making. United States Patent 5, 047,627 